\title{
$M A C C 1$ expression levels as a novel prognostic marker for colorectal cancer
}

\author{
HIROFUMI YAMAMOTO $^{1 *}$, NORIKATSU MIYOSHI ${ }^{2 *}$, KOSHI MIMORI $^{3}$, TOSHIKI HITORA $^{4}$, \\ MASAYOSHI TOKUOKA ${ }^{5}$, SHIKI FUJINO ${ }^{2}$, HALEY L. ELLIS ${ }^{6}$, HIDESHI ISHII $^{7}$, SHINGO NOURA $^{2}$, \\ MASAYUKI OHUE $^{2}$, MASAHIKO YANO ${ }^{2}$, YUICHIRO DOKI ${ }^{1}$ and MASAKI MORI ${ }^{1}$ \\ ${ }^{1}$ Department of Gastroenterological Surgery, Osaka University Graduate School of Medicine, Suita, Osaka 565-0871; \\ ${ }^{2}$ Department of Surgery, Osaka Medical Center for Cancer and Cardiovascular Diseases, Nakamichi, Osaka 537-8511; \\ ${ }^{3}$ Department of Molecular and Cellular Biology, Division of Molecular and Surgical Oncology, Kyushu University, \\ Medical Institute of Bioregulation, Beppu, Osaka 874-0838; ${ }^{4}$ Department of Surgery, Osaka Rosai Hospital, Sakai, \\ Osaka 591-8025; ${ }^{5}$ Department of Surgery, Yao Municipal Hospital, Yao, Osaka 581-0069, Japan; ${ }^{6}$ Human Oncology \\ and Pathogenesis Program, Memorial Sloan-Kettering Cancer Center, New York, NY 10065, USA; ${ }^{7}$ Department of \\ Frontier Science for Cancer and Chemotherapy, Osaka University, Yamadaoka, Suita, Osaka 565-0871, Japan
}

Received January 16, 2014; Accepted August 1, 2014

DOI: $10.3892 / 01.2014 .2460$

\begin{abstract}
Metastasis-associated in colon cancer-1 (MACC1) is key in promoting tumor proliferation and invasion, and is mediated by the hepatocyte growth factor $(H G F)$ and mesenchymal-epithelial transition factor. Previous reports have revealed that $M A C C 1$ is a novel oncogene that is expressed in various types of gastrointestinal cancer. The present study comprised of 174 patients who underwent curative surgery for colorectal cancer (CRC). The correlation between gene expression and clinical parameters of the patients was assessed. It was identified that patients exhibiting high $M A C C 1$ expression levels were statistically more susceptible to distant metastases and a poor prognosis, and those exhibiting low $M A C C 1$ expression showed improved disease-free and overall survival than those with high expression. Therefore, the present data indicates that $\mathrm{MACCl}$ expression levels may present as a prognostic factor in CRC patients.
\end{abstract}

\section{Introduction}

In developed countries where the aging population is increasing, cancer is one of the most prominent diseases with regard to public welfare and health measures. One in four mortalities in

Correspondence to: Dr Norikatsu Miyoshi, Department of Surgery, Osaka Medical Center for Cancer and Cardiovascular Diseases, 1-3-3, Nakamichi, Higashinari-ku, Osaka 537-8511, Japan E-mail: miyosi-no@mc.pref.osaka.jp

*Contributed equally

Key words: metastasis-associated in colon cancer-1, prognosis, colorectal cancer the USA, for example, is due to cancer (1). In the USA, the incidence of colorectal cancer (CRC) has increased significantly in recent years due to the changing lifestyle of the population and is currently one of the most frequently exhibited malignancies and leading causes of cancer-related mortality. The metastatic dissemination of primary tumors is directly associated with patient survival, and distant metastases, such as of the liver or lungs, are the major cause of mortality in CRC patients. Furthermore, metastatic disease is the most frequent reason for treatment failure (2). Therefore, the identification of genes that are responsible for the development and progression of CRC, and comprehension of the clinical significance of these genes is critical for the diagnosis and adequate treatment of CRC. The characterization of these key molecules is promising for the development of novel treatment strategies for CRC.

The hepatocyte growth factor $(H G F) /$ mesenchymal-epithelial transition factor (MET) signaling pathway was reported to have a key role in cellular growth, invasiveness and metastasis (3-5). The metastasis-associated in colon cancer-1 (MACC1) induces MET expression and promotes $H G F$-induced scattering, which the mitogen-activated protein kinase $(M A P K)$ signaling pathway prevents (6). This indicates that $M A C C l$ expression in primary tumors is associated with metastasis and results in a poor prognosis.

The aim of the present study was to analyze the correlation between $M A C C l$ expression levels, in tissue obtained from CRC patients, with their clinicopathological factors, and to investigate the possible functions of MACCl in the metastasis of CRC.

\section{Materials and methods}

Clinical tissue samples. One hundred and seventy-four patients (99 males and 75 females) with CRC underwent curative surgery of CRC and distant metastases (if present) at the Department of Gastroenterological Surgery, Osaka University Graduate School of Medicine and Medical Institute of Bioregulation at Kyusyu 
University (Osaka, Japan) between 1994 and 2003. No patients had received chemotherapy or radiotherapy prior to surgery. Primary CRC specimens and adjacent normal colorectal mucosa were obtained from patients following receipt of written informed consent, which was in accordance with the institutional ethical guidelines. The surgical specimens were fixed in formalin, processed through graded ethanol, and embedded in paraffin. The sections were stained with hematoxylin and eosin and Elastica van Gieson stain (Merck Millipore, Billerica, MA, USA), and the degree of histological differentiation, lymphatic invasion, and venous invasion was examined. Additionally, samples of each specimen were frozen in liquid nitrogen immediately after resection and stored at $-80^{\circ} \mathrm{C}$ until RNA extraction. Following surgery, the patients underwent follow-up blood examinations to assess the tumor markers, serum carcinoembryonic antigen and cancer antigen 19-9 and imaging, such as abdominal ultrasonography, computed tomography and chest $\mathrm{X}$-rays were conducted every 3-6 months. Postoperatively, stage III and IV patients received 5-fluorouracil-based chemotherapy [mFOLFOX6; $85 \mathrm{mg} / \mathrm{m}^{2}$ oxaliplatin and $2800 \mathrm{mg} / \mathrm{m}^{2} 5$-fluorouracil, for two weeks for a total of 12 courses of treatment; $300 \mathrm{mg} / \mathrm{m}^{2} /$ day UFT, for 28 days for five weeks for five courses of treatment; $2500 \mathrm{mg} / \mathrm{m}^{2} /$ day capecitabine for 14 days for three weeks for 8 courses of treatment, and/or $80 \mathrm{mg} / \mathrm{m}^{2} /$ day TS-1 (tegafur, gimestat and otastat potassium) for 28 days for six weeks and four courses of treatment]. Adjuvant therapeutic strategies were performed, except for stage I and II patients who received no chemotherapy, according to the guidelines laid out by the Japanese Society for Cancer of the Colon and Rectum (7). Clinicopathological factors were assessed according to the tumor node metastasis (TNM) classification system of the International Union Against Cancer (8). This study was approved by the ethics committee of Osaka University Graduate School of Medicine (Osaka, Japan).

RNA preparation and expression analysis. Total RNA was prepared using TRIzol reagent (Invitrogen Life Technologies, Carlsbad, CA, USA) or using DNase and a modified acid guanidinium-phenol-chloroform procedure (9). Reverse transcription (RT) was performed with SuperScript ${ }^{\mathrm{TM}}$ II (Invitrogen Life Technologies) or by the methods reported previously (10) and an $M A C C 1$ fragment was amplified by polymerase chain reaction (PCR). Two human MACC1 oligonucleotide primers were designed as follows: Forward, 5'-TTCTTTTGATTCCTCCGGTGA-3' and reverse, 5'-ACTCTGATGGGCATGTGCTG-3'. A PCR kit (Takara Ex Taq; Takara Bio Inc., Shiga, Japan) on a GeneAMP ${ }^{\circledR}$ PCR System 9600 (PE Applied Biosystems, Foster City, CA, USA) was used to perform 35 cycles of PCR with the following parameters: $95^{\circ} \mathrm{C}$ for $40 \mathrm{sec}, 45^{\circ} \mathrm{C}$ for $40 \mathrm{sec}$ and $72^{\circ} \mathrm{C}$ for $60 \mathrm{sec}$. An 8- $\mu \mathrm{l}$ aliquot of each reaction mixture was size-fractionated in a $1.5 \%$ agarose gel and visualized with ethidium bromide staining. To ensure the RNA was not degraded, a PCR assay with primers specific for the glyceraldehydes-3-phosphate dehydrogenase $(\mathrm{GAPDH})$ gene was performed for $1 \mathrm{~min}$ at $95^{\circ} \mathrm{C}, 1 \mathrm{~min}$ at $56^{\circ} \mathrm{C}$, and $1 \mathrm{~min}$ at $72^{\circ} \mathrm{C}$ for 30 cycles. The GAPDH primers were as follows: Forward, 5'-TTGGTATCGTGGAAGGACTCA-3' and reverse, 5'-TGTCATCATATTGGCAGGTT-3' and produced a 270-bp amplicon. Complementary DNA (cDNA) from Human Reference Total RNA (Clontech Laboratories, Mountain View,

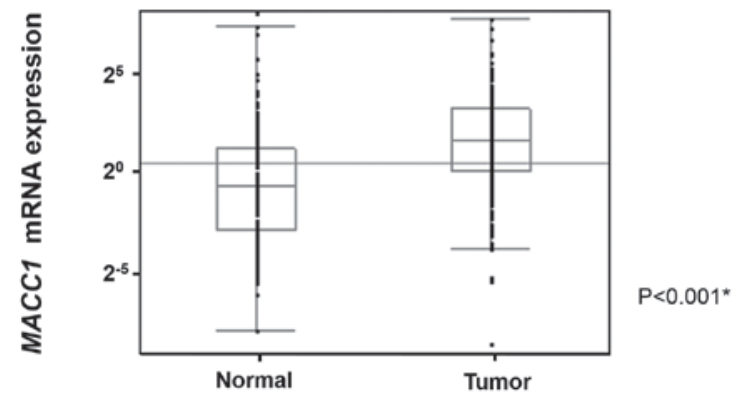

Figure 1. MACC1 mRNA expression levels in clinical tissue specimens. Quantitative reverse transcription-polymerase chain reaction on 174 paired clinical samples showed that 143 cases $(82.2 \%)$ exhibited higher levels of $M A C C 1$ mRNA in tumors than in the paired normal tissues. The mean $M A C C 1$ mRNA expression level in the tumor tissues (normalized to glyceraldehydes-3-phosphate dehydrogenase gene expression) was significantly different when compared with the corresponding normal tissues $(\mathrm{P}<0.001$, Wilcoxon-signed rank test).

CA, USA) was analyzed concurrently and served as a positive control. For quantitative assessment, RT-qPCR was performed using a LightCycler ${ }^{\circledR}$ FastStart DNA Master SYBR Green I kit (Roche Diagnostics, Tokyo, Japan) for cDNA amplification of $M A C C 1$ and GAPDH. The amplification protocol consisted of 35 cycles of denaturation at $95^{\circ} \mathrm{C}$ for $10 \mathrm{sec}$, annealing at $60^{\circ} \mathrm{C}$ for $10 \mathrm{sec}$, and elongation at $72^{\circ} \mathrm{C}$ for $10 \mathrm{sec}$. The products were then subjected to a temperature gradient from $55^{\circ} \mathrm{C}$ to $95^{\circ} \mathrm{C}$ with continuous fluorescence monitoring to produce a melting curve of the products. The expression ratios of the $M A C C 1 \mathrm{mRNA}$ copies in the tumor and normal tissues were calculated following normalization against the GAPDH mRNA expression.

Statistical analysis. The association between $M A C C l$ expression and patient clinicopathological factors was analyzed using the $\chi^{2}$ test. Kaplan-Meier survival curves were plotted and compared with the generalized log-rank test. Univariate and multivariate analyses were performed to identify prognostic factors using a Cox proportional hazards regression model. The in vitro assay values were analyzed using the Wilcoxon signed-rank test. All tests were analyzed with JMP software (SAS Institute Inc., Cary, NC, USA) and $\mathrm{P}<0.05$ was considered to indicate a statistically significant difference.

\section{Results}

Expression levels of MACC1 in clinical tissue specimens. RT-qPCR analysis was performed on tissues from primary $\mathrm{CRC}$ and adjacent normal colorectal regions. MACCl expression was calculated by normalising it to GAPDH expression for each tumor or normal tissue sample (Fig. 1). A significant difference was identified between the tissue types, with the average expression in tumor tissues larger than that of the corresponding normal tissues. In the following analyses, $M A C C 1$ expression, normalized to $G A P D H$ expression, in tumor tissue was calculated following division by MACC1/ $G A P D H$ expression in the normal tissue.

Expression levels of MACCl and patient clinicopathological characteristics. For the clinicopathological evaluation, experimental samples were divided into two groups according to the 
Table I. Clinicopathological factors and MACC1 mRNA expression in 174 colorectal cancer tissue samples.

\begin{tabular}{|c|c|c|c|}
\hline Factor & $\begin{array}{c}\text { Low expression } \\
\mathrm{n}=31(\%)\end{array}$ & $\begin{array}{l}\text { High expression } \\
n=143(\%)\end{array}$ & P-value \\
\hline \multicolumn{4}{|l|}{ Age (years) } \\
\hline$<68$ & $19(61.3)$ & 70 (48.9) & \multirow[t]{2}{*}{0.212} \\
\hline$\geq 68$ & $12(38.7)$ & $73(51.1)$ & \\
\hline \multicolumn{4}{|l|}{ Gender } \\
\hline Male & $13(41.9)$ & $86(60.1)$ & \multirow[t]{2}{*}{0.063} \\
\hline Female & $18(58.1)$ & $57(39.9)$ & \\
\hline \multicolumn{4}{|c|}{ Histological grade } \\
\hline Wel-Mod & $31(100)$ & $134(93.7)$ & \multirow[t]{2}{*}{0.151} \\
\hline Por-Muc & $0(0)$ & $9(6.3)$ & \\
\hline \multicolumn{4}{|l|}{ Tumor size } \\
\hline$<30 \mathrm{~mm}$ & $11(35.5)$ & $41(28.7)$ & \multirow[t]{2}{*}{0.452} \\
\hline$\geq 30 \mathrm{~mm}$ & $20(64.5)$ & $102(71.3)$ & \\
\hline \multicolumn{4}{|c|}{ Tumor invasion } \\
\hline Tis & $7(22.6)$ & $8(5.6)$ & \multirow[t]{5}{*}{$0.006^{\mathrm{a}}$} \\
\hline $\mathrm{T} 1$ & $4(12.9)$ & $12(8.4)$ & \\
\hline $\mathrm{T} 2$ & $8(25.8)$ & $23(16.1)$ & \\
\hline $\mathrm{T} 3$ & $9(29.0)$ & $74(51.7)$ & \\
\hline $\mathrm{T} 4$ & $3(9.7)$ & $26(18.2)$ & \\
\hline \multicolumn{4}{|c|}{ Lymph node metastasis } \\
\hline No & $23(74.2)$ & $83(58.0)$ & \multirow[t]{2}{*}{0.094} \\
\hline N1-2 & $8(25.8)$ & $60(42.0)$ & \\
\hline \multicolumn{4}{|c|}{ Lymphatic invasion } \\
\hline Absent & $17(54.8)$ & $83(58.0)$ & \multirow[t]{2}{*}{0.743} \\
\hline Present & $14(45.2)$ & $60(42.0)$ & \\
\hline \multicolumn{4}{|c|}{ Venous invasion } \\
\hline Absent & $27(87.1)$ & $111(77.6)$ & \multirow[t]{2}{*}{0.237} \\
\hline Present & $4(12.9)$ & $32(22.4)$ & \\
\hline \multicolumn{4}{|c|}{ Distant metastasis } \\
\hline M0 & $31(100)$ & 134 (93.7) & \multirow[t]{2}{*}{0.151} \\
\hline M1 & $0(0)$ & $9(6.3)$ & \\
\hline
\end{tabular}

The tumor node metastasis classification of the International Union Against Cancer (8) was used to determine the extent of tumor invasion, lymph node metastasis and distant metastasis. Wel, well-differentiated adenocarcinoma; Mod, moderately differentiated adenocarcinoma; Por, poorly differentiated adenocarcinoma; Muc, mucinous adenocarcinoma; Tis, carcinoma in situ. ${ }^{\mathrm{a}} \mathrm{P}<0.05$ indicates a statistically significant value.

expression status. Patients with values $>1$ (MACCl expression level of tumor tissue greater than that of the corresponding normal tissue) were assigned to the high-expression group and patients with values $<1$ were assigned to the low-expression group. The clinicopathological factors that were associated with the MACCl expression status of the 174 patients are summarized in Table I. The data indicates that the level of $M A C C 1$ expression was not significantly correlated with the clinicopathological factors.

Association between MACC1 expression and prognosis. The data showed that the postoperative disease-free survival rate was significantly lower in patients in the high-expression group than that of the low-expression group ( $\mathrm{P}=0.019$; Fig. 2). The postoperative overall survival rate was lower in patients in the high-expression group than in the patients in the low-expression group ( $\mathrm{P}=0.054$; Fig. 3$)$. The median follow-up was 4.1 years. Table II shows the results of the univariate and multivariate analyses for factors associated with disease-free survival. The univariate analysis showed that age $(\mathrm{P}=0.035)$, tumor invasion $(\mathrm{P}<0.001)$, lymph node metastasis $(\mathrm{P}<0.001)$, lymphatic invasion $(\mathrm{P}<0.001)$, venous invasion $(\mathrm{P}=0.011)$, distant metastasis $(\mathrm{P}<0.001)$ and $M A C C 1$ expression $(\mathrm{P}=0.005)$ were significantly correlated with disease-free survival. The multivariate regression analysis indicated in the $M A C C 1$ high-expression group (hazard ratio [HR], 2.27; 
Table II. Univariate and multivariate analyses for disease-free survival (Cox proportional hazards regression model).

\begin{tabular}{|c|c|c|c|c|c|c|}
\hline \multirow[b]{2}{*}{ Factor } & \multicolumn{3}{|c|}{ Univariate analysis } & \multicolumn{3}{|c|}{ Multivariate analysis } \\
\hline & HR & $95 \% \mathrm{CI}$ & P-value & HR & $95 \% \mathrm{CI}$ & P-value \\
\hline $\begin{array}{l}\text { Age (years) } \\
(<68 / \geq 68)\end{array}$ & 2.10 & $1.05-4.49$ & 0.035 & 1.99 & $0.98-4.28$ & 0.056 \\
\hline $\begin{array}{l}\text { Gender } \\
\text { (Male/Female) }\end{array}$ & 1.46 & $0.79-3.12$ & 0.289 & & & \\
\hline $\begin{array}{l}\text { Histological grade } \\
\text { (Por-Muc/Wel-Mod) }\end{array}$ & 1.52 & $0.61-2.79$ & 0.304 & & & \\
\hline $\begin{array}{l}\text { Tumor size }(\mathrm{mm}) \\
(\geq 30 /<30)\end{array}$ & 1.38 & $0.93-2.18$ & 0.106 & & & \\
\hline $\begin{array}{l}\text { Tumor invasion } \\
\text { (T3-4/Tis-2) }\end{array}$ & 7.11 & $2.53-29.64$ & $<0.001^{\mathrm{a}}$ & 1.69 & $0.52-7.62$ & $0.403^{\mathrm{a}}$ \\
\hline $\begin{array}{l}\text { Lymph node metastasis } \\
\text { (N1-2/N0) }\end{array}$ & 5.87 & $2.83-13.35$ & $<0.001^{\mathrm{a}}$ & 3.15 & $1.44-7.48$ & $0.003^{\mathrm{a}}$ \\
\hline $\begin{array}{l}\text { Lymphatic invasion } \\
\text { (Present/Absent) }\end{array}$ & 3.71 & $1.85-7.94$ & $<0.001^{\mathrm{a}}$ & 2.87 & $1.28-6.86$ & $0.010^{\mathrm{a}}$ \\
\hline $\begin{array}{l}\text { Venous invasion } \\
\text { (Present/Absent) }\end{array}$ & 2.62 & $1.25-5.21$ & $0.011^{\mathrm{a}}$ & 2.24 & $0.98-5.06$ & 0.054 \\
\hline $\begin{array}{r}\text { Metastasis } \\
(\mathrm{M} 1 / \mathrm{M} 0)\end{array}$ & 10.18 & $4.25-21.95$ & $<0.001^{\mathrm{a}}$ & 12.83 & $4.62-34.57$ & $<0.001^{\mathrm{a}}$ \\
\hline $\begin{array}{l}\text { MACCl expression } \\
\text { (High/Low) }\end{array}$ & 2.736 & $1.26-11.53$ & $0.005^{\mathrm{a}}$ & 2.27 & $1.01-9.71$ & $0.044^{\mathrm{a}}$ \\
\hline
\end{tabular}

Clinicopathological factors, including tumor invasion, lymph node metastasis and distant metastasis were assessed according to the tumor node metastasis classification of the International Union Against Cancer (8). HR, hazard ratio; CI, confidence interval; Por, poorly differentiated adenocarcinoma; Muc, mucinous adenocarcinoma; Wel, well differentiated adenocarcinoma; Mod, moderately differentiated adenocarcinoma; Tis, carcinoma in situ; $M A C C 1$, metastasis-associated in colon cancer-1. ${ }^{\mathrm{a}} \mathrm{P}<0.05$ indicates a statistically significant value.

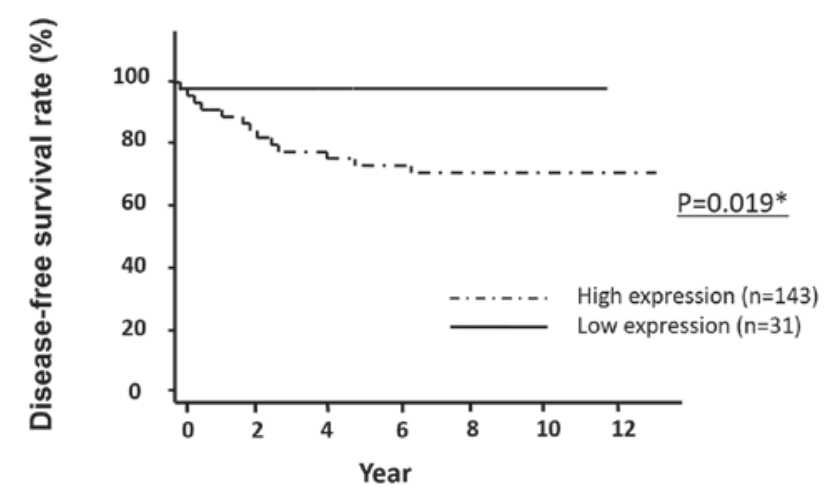

Figure 2. Disease-free survival curves based on the MACC1 mRNA expression status of colorectal cancer patients following curative surgery. The postoperative disease-free survival rate was significantly lower in patients in the high-MACC1 expression group compared with the low-expression group $(\mathrm{P}=0.019$, log-rank test $)$.

95\% confidence interval $[\mathrm{CI}], 1.01-9.71 ; \mathrm{P}=0.044)$, lymph node metastasis (HR, 3.15; 95\% CI, 1.44-7.48; $\mathrm{P}=0.003$ ), lymphatic invasion (HR, 2.87; 95\% CI, 1.28-6.86; $\mathrm{P}=0.010)$ and distant metastasis (HR, 12.83; 95\%; CI, 4.62-34.57; P<0.001) were independent predictors of disease-free survival.

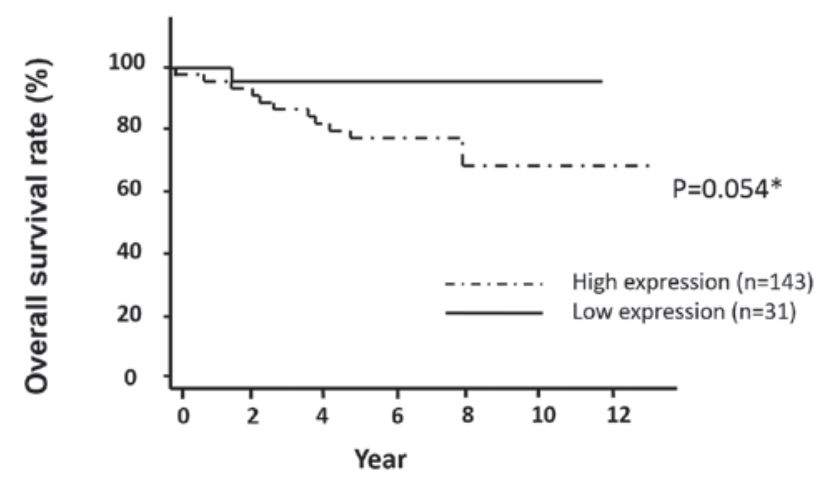

Figure 3. Overall survival curves based on the MACC1 mRNA expression status of colorectal cancer patients. The postoperative overall survival rate was significantly lower in patients in the high-MACC1 expression group compared with the low-expression group $(\mathrm{P}=0.054$, log-rank test).

\section{Discussion}

$H G F$ activates the $H G F / M E T$ signaling pathway, which is involved in metastasis of CRC. The $H G F$ receptor, the gene for the receptor tyrosine kinase, $M E T$ was identified as the first transcriptional target of MACC1 (11). MACCl is located 
on chromosome 7 and was identified through genome-wide expression analyses conducted on primary and metastatic colon cancer (12). MACCl binds to, and promotes, MET gene expression by translocating from the cytoplasm to the nucleus, leading to migration, invasion and metastasis.

The present study demonstrated that $M A C C l$ expression levels are an independent factor of disease-free survival for CRC. Tumor malignancy was identified to correlate with $M A C C 1$ expression levels and $M A C C 1$ expression may affect the values of other prognostic factors in multivariate analysis, such as distant metastasis, which was found to be significant in univariate analysis. $M A C C l$ expression levels were a significant prognostic factor, reflecting disease-free survival as well as the occurrence of distant metastasis. The present study is considered to be important as it has provided analyses of a large number of samples, which demonstrate that MACC1 expression levels may be used as a statistically significant marker for CRC metastasis following curative resection, along with other reported predictors (13). The present results support recent reports that a $M A C C 1$-dependent signaling pathway is involved in the progression of CRC $(12,14,15)$.

It is useful to determine the necessity for intensive follow-up and adjuvant CRC therapy by predicting recurrence and metastases following curative surgical resection (16-18). Certain patients respond well to the treatment of CRC, however others do not. Thus, more precise and personalized predictions and strategies for treating metastases are required (19). In the present study, the clinicopathological analysis of a large number of patients revealed that $\mathrm{CRC}$ samples exhibiting a low expression of $M A C C l$ were an improved predictor for disease-free and overall survival when compared with the high-expression group. The data indicates that $M A C C 1$ expression levels are an effective predictor of CRC prognosis.

In CRC, various adjuvant chemotherapeutic strategies are facilitative during certain disease stages and indicate the usefulness of less invasive surgery for CRC (13,16-18,20-26). For these cases, an informative prognostic marker, which is independent from the traditional TNM classification and contributes to diagnosis and treatment, is important. In conclusion, the present data indicates $M A C C 1$ expression levels as a potential prognostic marker for CRC. Whilst improved preoperative and postoperative treatment strategies for CRC, such as chemo- and radiotherapy combined with surgery, have contributed to the reduction of recurrences, eventually half of the cases metastasize despite the systemic chemotherapy and surgery (27). Adjuvant chemotherapy for CRC is advantageous in cases where recurrence is considered to be likely. In these cases, $M A C C 1$ expression level analysis may present as a tool to predict poor prognosis and provide adequate treatment for patients.

\section{References}

1. Jemal A, Siegel R, Xu J and Ward E: Cancer statistics, 2010. CA Cancer J Clin 60: 277-300, 2010.

2. Stein U and Schlag PM: Clinical, biological, and molecular aspects of metastasis in colorectal cancer. Recent Results Cancer Res 176: 61-80, 2007.

3. Birchmeier C, Birchmeier W, Gherardi E and Vande Woude GF: Met, metastasis, motility and more. Nat Rev Mol Cell Biol 4: 915-925, 2003.

4. Mazzone M and Comoglio PM: The Met pathway: master switch and drug target in cancer progression. FASEB J 20: 1611-1621, 2006.
5. Sattler M and Salgia R: c-Met and hepatocyte growth factor: potential as novel targets in cancer therapy. Curr Oncol Rep 9: 102-108, 2007.

6. Potempa S and Ridley AJ: Activation of both MAP kinase and phosphatidylinositide 3-kinase by Ras is required for hepatocyte growth factor/scatter factor-induced adherens junction disassembly. Mol Biol Cell 9: 2185-2200, 1998.

7. Watanabe T, Itabashi M, Shimada Y, et al; Japanese Society for Cancer of the Colon and Rectum: Japanese Society for Cancer of the Colon and Rectum (JSCCR) guidelines 2010 for the treatment of colorectal cancer. Int J Clin Oncol 17: 1-29, 2012.

8. Sobin LH and Fleming ID: TNM classification of malignant tumors, fifth edition (1997). Union Internationale Contre le Cancer and the American Joint Committee on Cancer. Cancer 80: 1803-1804, 1997.

9. Mimori K, Mori M, Shiraishi T, et al: Clinical significance of tissue inhibitor of metalloproteinase expression in gastric carcinoma. Br J Cancer 76: 531-536, 1997.

10. Mori M, Staniunas RJ, Barnard GF, et al: The significance of carbonic anhydrase expression in human colorectal cancer. Gastroenterology 105: 820-826, 1993 .

11. Stein U: MACC1-a novel target for solid cancers. Expert Opin Ther Targets 17: 1039-1052, 2013.

12. Stein U, Walther W, Arlt F, et al: MACC1, a newly identified key regulator of HGF-MET signaling, predicts colon cancer metastasis. Nat Med 15: 59-67, 2009.

13. André T, Quinaux E, Louvet C, et al: Phase III study comparing a semimonthly with a monthly regimen of fluorouracil and leucovorin as adjuvant treatment for stage II and III colon cancer patients: final results of GERCOR C96.1. J Clin Oncol 25: 3732-3738, 2007.

14. Juneja M, Ilm K, Schlag PM and Stein U: Promoter identification and transcriptional regulation of the metastasis gene MACC1 in colorectal cancer. Mol Oncol 7: 929-943, 2013.

15. Zhang Y, Wang Z, Chen M, et al: MicroRNA-143 targets MACC to inhibit cell invasion and migration in colorectal cancer. Mol Cancer 11: 23, 2012.

16. Wolpin BM and Mayer RJ: Systemic treatment of colorectal cancer. Gastroenterology 134: 1296-1310, 2008.

17. Kornmann M, Formentini A, Ette C, et al: Prognostic factors influencing the survival of patients with colon cancer receiving adjuvant 5-FU treatment. Eur J Surg Oncol 34: 1316-1321, 2008.

18. Bathe OF, Dowden S, Sutherland F, et al: Phase II study of neoadjuvant 5-FU + leucovorin + CPT-11 in patients with resectable liver metastases from colorectal adenocarcinoma. BMC Cancer 4: 32 , 2004.

19. Sadanandam A, Lyssiotis CA, Homicsko K, et al: A colorectal cancer classification system that associates cellular phenotype and responses to therapy. Nat Med 19: 619-625, 2013.

20. Iijima M, Kano Y, Nohno T and Namba M: Cloning of cDNA with possible transcription factor activity at the G1-S phase transition in human fibroblast cell lines. Acta Med Okayama 50: 73-77, 1996.

21. Hansen WJ, Cowan NJ and Welch WJ: Prefoldin-nascent chain complexes in the folding of cytoskeletal proteins. J Cell Biol 145: 265-277, 1999.

22. Hodgson G, Hager JH, Volik S, et al: Genome scanning with array CGH delineates regional alterations in mouse islet carcinomas. Nat Genet 29: 459-464, 2001.

23. Lacy AM, García-Valdecasas JC, Delgado S, et al: Laparoscopy-assisted colectomy versus open colectomy for treatment of non-metastatic colon cancer: a randomised trial. Lancet 359: 2224-2229, 2002.

24. Weeks JC, Nelson H, Gelber S, et al: Short-term quality-of-life outcomes following laparoscopic-assisted colectomy vs open colectomy for colon cancer: a randomized trial. JAMA 287: 321-328, 2002.

25. No authors listed: Laparoscopically assisted colectomy is as safe and effective as open colectomy in people with colon cancer Abstracted from: Nelson H, Sargent D, Wieand HS, et al; for the Clinical Outcomes of Surgical Therapy Study Group. A comparison of laparoscopically assisted and open colectomy for colon cancer. $\mathrm{N}$ Engl J Med 350: 2050-2059, 2004.

26. Jayne DG, Guillou PJ, Thorpe H, et al; UK MRC CLASICC Trial Group: Randomized trial of laparoscopic-assisted resection of colorectal carcinoma: 3-year results of the UK MRC CLASICC Trial Group. J Clin Oncol 25: 3061-3068, 2007.

27. Koshariya M, Jagad RB, Kawamoto J, et al: An update and our experience with metastatic liver disease. Hepatogastroenterology 54: 2232-2239, 2007. 